\title{
Accelerated Particle Swarm for Optimum Design of Frame Structures
}

\author{
S. Talatahari, ${ }^{1}$ E. Khalili, ${ }^{2}$ and S. M. Alavizadeh ${ }^{3}$ \\ ${ }^{1}$ Marand Faculty of Engineering, University of Tabriz, Tabriz 51666-14766, Iran \\ ${ }^{2}$ Department of Engineering, Islamic Azad University, Ahar Branch, Ahar 54516, Iran \\ ${ }^{3}$ Department of Structural Engineering, Islamic Azad University, Shabestar Branch, \\ Shabestar 57168-14758, Iran
}

Correspondence should be addressed to S. Talatahari; talatahari@tabrizu.ac.ir

Received 29 November 2012; Revised 29 December 2012; Accepted 30 December 2012

Academic Editor: Fei Kang

Copyright (c) 2013 S. Talatahari et al. This is an open access article distributed under the Creative Commons Attribution License, which permits unrestricted use, distribution, and reproduction in any medium, provided the original work is properly cited.

\begin{abstract}
Accelerated particle swarm optimization (APSO) is developed for finding optimum design of frame structures. APSO shows some extra advantages in convergence for global search. The modifications on standard PSO effectively accelerate the convergence rate of the algorithm and improve the performance of the algorithm in finding better optimum solutions. The performance of the APSO algorithm is also validated by solving two frame structure problems.
\end{abstract}

\section{Introduction}

Optimum design of frame structures are inclined to determine suitable sections for elements that fulfill all design requirements while having the lowest possible cost. In this issue, optimization provides engineers with a variety of techniques to deal with these problems [1]. These techniques can be categorized as two general groups: classical methods and metaheuristic approaches [2]. Classical methods are often based on mathematical programming, and many of metaheuristic methods make use of the ideas from nature and do not suffer the discrepancies of mathematical programming [3-8].

Particle swarm optimization (PSO), one of meta-heuristic algorithms, is based on the simulation of the social behavior of bird flocking and fish schooling. PSO is the most successful swarm intelligence inspired optimization algorithms. However, the local search capability of PSO is poor [9], since premature convergence occurs often. In order to overcome these disadvantages of PSO, many improvements have been proposed. Shi and Eberhart [10] introduced a fuzzy system to adapt the inertia weight for three benchmark test functions. Liu et al. [11] proposed center particle swarm optimization by adding a center particle into PSO to improve the performance. An improved quantum-behaved PSO was proposed by Xi et al. [12]. Jiao et al. [13] proposed the dynamic inertia weight PSO, by defining a dynamic inertia weight to decrease the inertia factor in the velocity update equation of the original PSO. Yang et al. [14] proposed another dynamic inertia weight to modify the velocity update formula in a method called modified particle swarm optimization with dynamic adaptation.

A number of studies have applied the PSO and improved it to be used in the field of structural engineering [15-21]. In this study, we developed an improved PSO, so-called accelerated particle swarm optimization (APSO) [22], to find optimum design of frame structures. The resulted method is then tested by some numerical examples to estimate its potential for solving structural optimization problems.

\section{Statement of Structural Optimization Problem}

Optimum design of structures includes finding optimum sections for members that minimizes the structural weight $W$. 
This minimum design should also satisfy inequality constraints that limit design variables and structural responses. Thus, the optimal design of a structure is formulated as [23]

$$
\begin{aligned}
& \text { minimize } W(\{x\})=\sum_{i=1}^{n} \gamma_{i} \cdot A_{i} \cdot l_{i} \\
& \text { subject to }: g_{\min } \leq g_{i}(\{x\}) \leq g_{\max }, \quad i=1,2,3, \ldots, m,
\end{aligned}
$$

where $W(\{x\})$ is the weight of the structure; $n$ and $m$ are the number of members making up the structure and the number of total constraints, respectively; max and min denote upper and lower bounds, respectively; $g(\{x\})$ denotes the constraints considered for the structure containing interaction constraints as well as the lateral and interstory displacements, as follows.

The maximum lateral displacement:

$$
g^{\Delta}=\frac{\Delta_{T}}{H}-R \geq 0
$$

The interstory displacements:

$$
g_{j}^{d}=\frac{d_{j}}{h_{j}}-R_{I} \geq 0, \quad j=1,2, \ldots, n s,
$$

where $\Delta_{T}$ is the maximum lateral displacement; $H$ is the height of the frame structure; $R$ is the maximum drift index; $d_{j}$ is the inter-story drift; $h_{j}$ is the story height of the $j$ th floor; $n s$ is the total number of stories; $R_{I}$ is the inter-story drift index permitted by the code of the practice.

LRFD interaction formula constraints (AISC 2001 [24, Equation H1-1a,b]):

$$
\begin{gathered}
g_{i}^{I}=\frac{P_{u}}{2 \phi_{c} P_{n}}+\left(\frac{M_{u x}}{\phi_{b} M_{n x}}+\frac{M_{u y}}{\phi_{b} M_{n y}}\right)-1 \geq 0 \quad \text { for } \frac{P_{u}}{\phi_{c} P_{n}}<0.2, \\
g_{i}^{I}=\frac{P_{u}}{\phi_{c} P_{n}}+\frac{8}{9}\left(\frac{M_{u x}}{\phi_{b} M_{n x}}+\frac{M_{u y}}{\phi_{b} M_{n y}}\right)-1 \geq 0 \quad \text { for } \frac{P_{u}}{\phi_{c} P_{n}} \geq 0.2,
\end{gathered}
$$

where $P_{u}$ is the required strength (tension or compression); $P_{n}$ is the nominal axial strength (tension or compression); $\phi_{c}$ is the resistance factor $\left(\phi_{c}=0.9\right.$ for tension, $\phi_{c}=0.85$ for compression); $M_{u x}$ and $M_{u y}$ are the required flexural strengths in the $x$ and $y$ directions, respectively; $M_{n x}$ and $M_{n y}$ are the nominal flexural strengths in the $x$ and $y$ directions (for two-dimensional structures, $M_{n y}=0$ ); $\phi_{b}$ is the flexural resistance reduction factor $\left(\phi_{b}=0.90\right)$.

For the proposed method, it is essential to transform the constrained optimization problem to an unconstraint one. A detailed review of some constraint-handling approaches is presented in [25]. In this study, a modified penalty function method is utilized for handling the design constraints which is calculated using the following formulas [2]:

$$
\begin{aligned}
& g_{i} \leq o \Longrightarrow \Phi_{g}^{(i)}=0, \\
& g_{i}>o \Longrightarrow \Phi_{g}^{(i)}=g_{i} .
\end{aligned}
$$

The objective function that determines the fitness of each particle is defined as

$$
\operatorname{Mer}^{k}=\varepsilon_{1} \cdot W^{k}+\varepsilon_{2} \cdot\left(\sum \Phi_{g}^{(i)}\right)^{\varepsilon_{3}}
$$

where Mer is the merit function to be minimized; $\varepsilon_{1}, \varepsilon_{2}$, and $\varepsilon_{3}$ are the coefficients of merit function; $\Phi_{g}^{(i)}$ denotes the summation of penalties. In this study, $\varepsilon_{1}$ and $\varepsilon_{2}$ are set to 1 and $W$ (the weight of structure), respectively, while the value of $\varepsilon_{3}$ is taken as 0.85 in order to achieve a feasible solution [26]. Before calculating $\Phi_{g}^{(i)}$, we first determine the weight of the structures generated by the particles, and if it becomes smaller than the so far best solution, then $\Phi_{g}^{(i)}$ will be calculated; otherwise the structural analysis does not perform. This methodology will decrease the required computational costs, considerably.

\section{Canonical Particle Swarm Optimization (PSO)}

The PSO algorithm, inspired by social behavior simulation $[27,28]$, is a population-based optimization algorithm which involves a number of particles that move through the search space, and their positions are updated based on the best positions of individual particles (called $x_{i}^{*}$ ) and the best of the swarm (called $g^{*}$ ) in each iteration. This matter is shown mathematically as the following equations:

$$
\begin{gathered}
v_{i}^{t+1}=w \cdot v_{i}^{t}+\alpha \cdot \operatorname{rand}_{1}\left(x_{i}^{*}-x_{i}^{t}\right)+\beta \cdot \operatorname{rand}_{2}\left(g_{i}^{*}-x_{i}^{t}\right) \\
x_{i}^{t+1}=x_{i}^{t}+v_{i}^{t+1}
\end{gathered}
$$

where $x_{i}$ and $v_{i}$ represent the current position and the velocity of the $i$ th particle, respectively; $\operatorname{rand}_{1}$ and rand $_{2}$ represent random numbers between 0 and $1 ; x_{i}^{*}$ is the best position visited by each particle itself; $g^{*}$ corresponds to the global best position in the swarm up to iteration $k ; \alpha$ and $\beta$ represent cognitive and social parameters, respectively. According to Kennedy and Eberhart [27], these two constants are set to 2 in order to make the average velocity change coefficient close to one. $W$ is a weighting factor (inertia weight) which controls the trade-off between the global exploration and the local exploitation abilities of the flying particles. A larger inertia weight makes the global exploration easier, while a smaller inertia weight tends to facilitate local exploitation. The inertia weight can be reduced linearly from 0.9 to 0.4 during the optimization process [29].

\section{Accelerated Particle Swam Optimization}

The standard PSO uses both the current global best $g^{*}$ and the individual best $x^{*}$. The reason of using the individual best is primarily to increase the diversity in the quality solutions; however, this diversity can be simulated using some randomness. Subsequently, there is no compelling reason for using the individual best, unless the optimization problem of interest is highly nonlinear and multimodal [22]. 


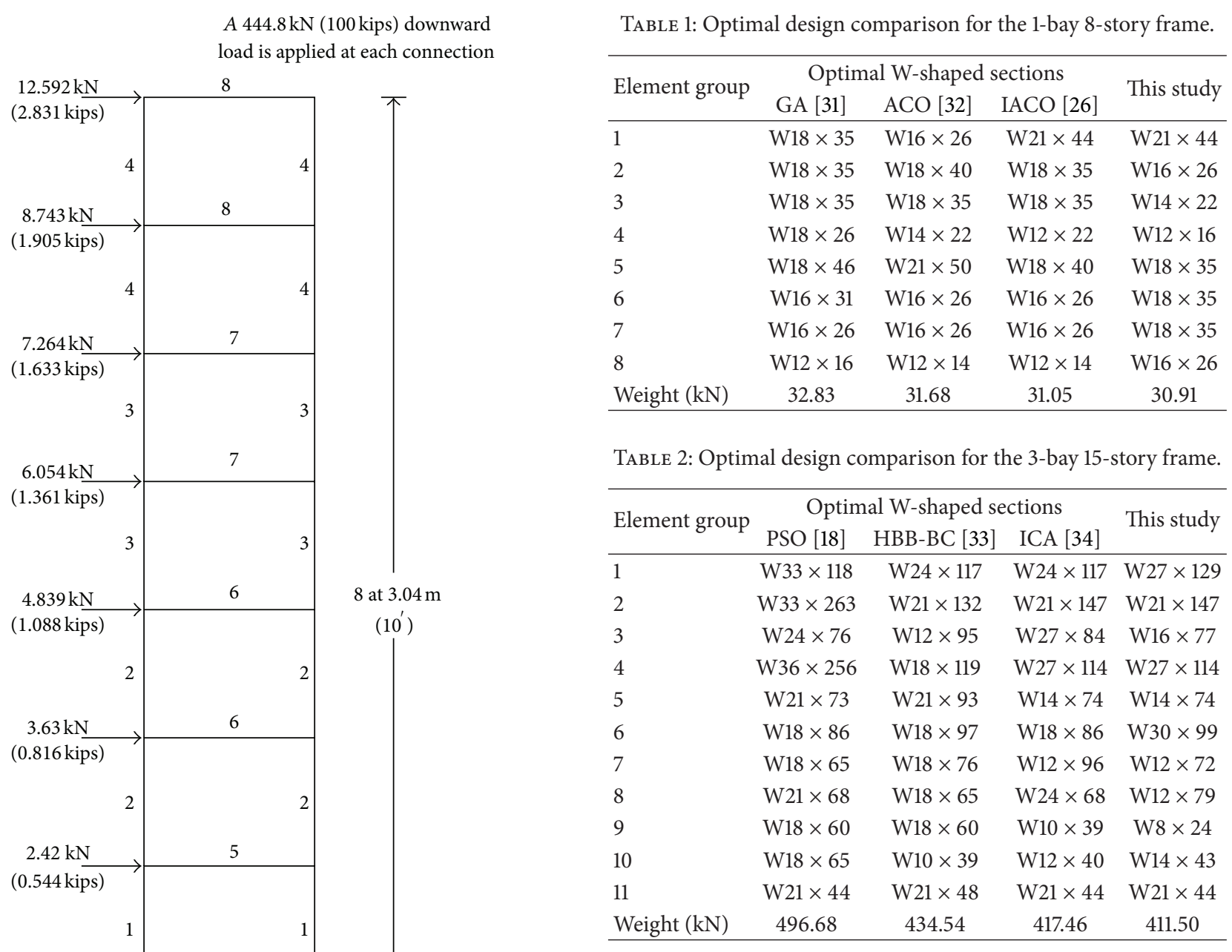

This simpler version will give the same order of convergence [30]. Typically, $\alpha=0.1 L-0.5 L$, where $L$ is the scale of each variable, while $\beta=0.2-0.7$ is sufficient for most applications. It is worth pointing out that the velocity does not appear in (10), and there is no need to deal with initialization of velocity vectors. Therefore, the APSO is much simpler. Comparing with many PSO variants, the APSO uses only two parameters, and the mechanism is simple to understand. A further improvement to the accelerated PSO is to reduce the randomness as iterations proceed. This means that we can use a monotonically decreasing function. In our implementation, we use [30]

$$
\alpha=0.7^{t},
$$

where $t \in\left[0, t_{\max }\right]$ and $t_{\max }$ is the maximum number of iterations.

\section{Numerical Examples}

This section presents the numerical examples to evaluate the capability of the new algorithm in finding the optimal design of the steel structures. The final results are compared to the solutions of other methods to show the efficiency of the present approach. The proposed algorithm is coded in Matlab, and structures are analyzed using the direct stiffness to increase the convergence even further, we can also write the update of the location in a single step, as

$$
x_{i}^{t+1}=(1-\beta) x_{i}^{t}+\beta g^{*}+\alpha r .
$$




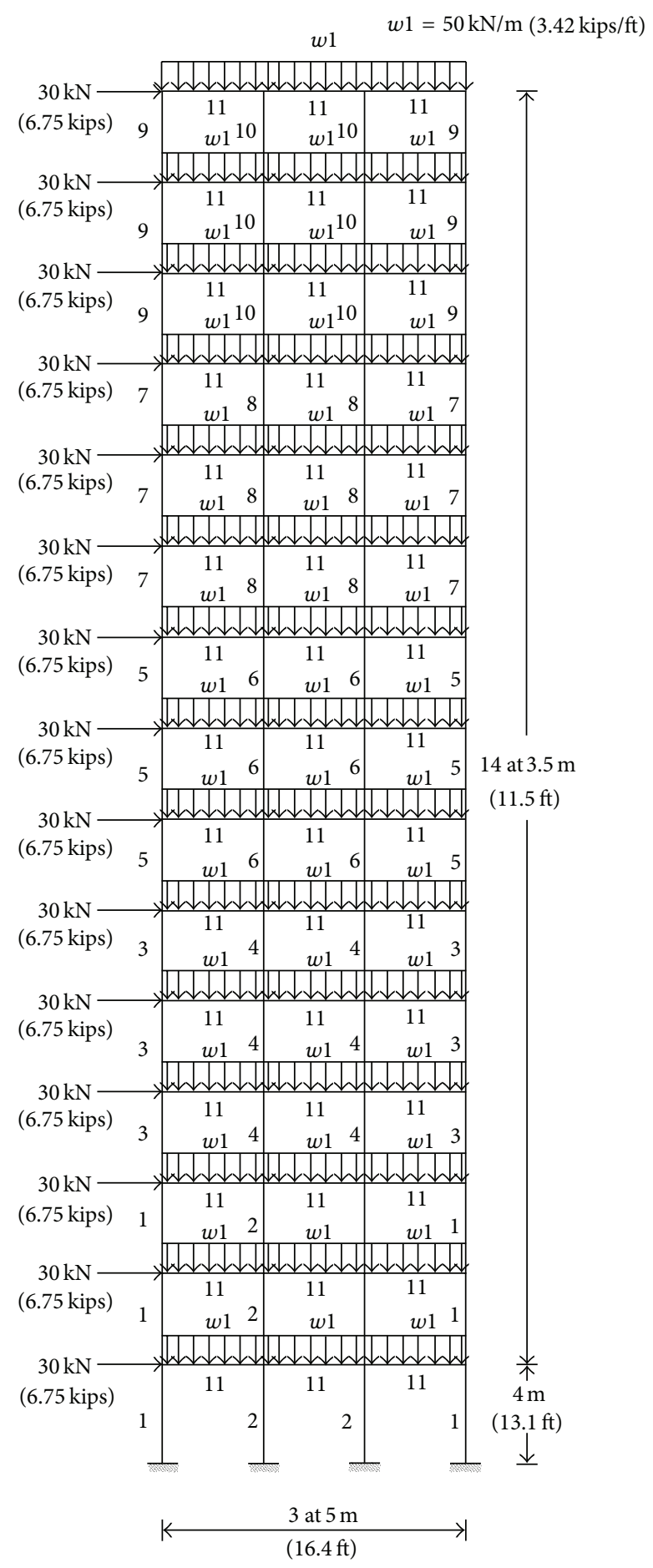

Figure 2: Topology of the 3-bay 15-story frame.

method. The steel members used for the design consist of 267 $\mathrm{W}$-shaped sections from the AISC database.

5.1. 1-Bay 8-Story Frame. Figure 1 shows the configuration of the 1-bay 8-story framed structure and applied loads. Several researchers have developed design procedures for this frame; Camp et al. [31] used a genetic algorithm, Kaveh and Shojaee

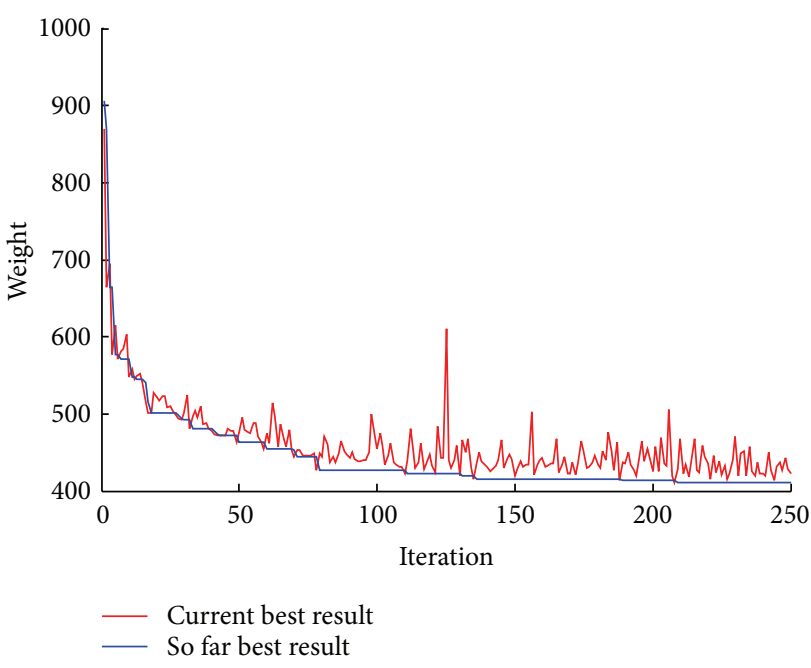

FIGURE 3: The convergence history for the 3-bay 15-story frame.

[32] utilized ACO, and Kaveh and Talatahari [26] applied an improved ACO to solve this problem.

The APSO algorithm found the optimal weight of the onebay eight-story frame to be $30.91 \mathrm{kN}$ which is the best one compared to the other method. Table 1 lists the optimal values of the eight design variables obtained by this research and compares them with other results.

5.2. Design of a 3-Bay 15-Story Frame. The configuration and applied loads of a 3-bay 15-story frame structure is shown in Figure 2. The sway of the top story is limited to $23.5 \mathrm{~cm}$ (9.25 in). The material has a modulus of elasticity equal to $E=200 \mathrm{GPa}$ and a yield stress of $F_{y}=248.2 \mathrm{MPa}$.

The effective length factors of the members are calculated as $K_{x} \geq 0$ for a sway-permitted frame, and the out-of-plane effective length factor is specified as $K_{y}=1.0$. Each column is considered as non-braced along its length, and the nonbraced length for each beam member is specified as one-fifth of the span length.

The optimum design of the frame obtained by using APSO has the minimum weight of $411.50 \mathrm{kN}$. The optimum designs for PSO [18], HBB-BC [33], and ICA [34] had the weights of $496.68 \mathrm{kN}, 434.54 \mathrm{kN}$, and $417.46 \mathrm{kN}$, respectively. Table 2 summarizes the optimal results for these different algorithms. Clearly, it can be seen that the present algorithm can find the better design. Figure 3 provides the convergence history for this example obtained by the APSO.

\section{Conclusions}

The APSO algorithm, as an improved meta-heuristic algorithm, is developed to solve frame structural optimization problems. Optimization software based on the APSO algorithm was coded in the Matlab using object-oriented technology. A methodology to handle the constraints is also developed in a way that we first determine the weight of the structures generated by the particles, and if they become smaller than the so far best solution, then the structural 
analyses are performed. Two test problems were studied using the optimization program to show the efficiency of the algorithm. The comparison of the results of the new algorithm with those of other algorithms shows that the APSO algorithm provides results as good as or better than other algorithms and can be used effectively for solving engineering problems.

\section{References}

[1] A. Kaveh and S. Talatahari, "Optimal design of skeletal structures via the charged system search algorithm," Structural and Multidisciplinary Optimization, vol. 41, no. 6, pp. 893-911, 2010.

[2] A. Kaveh, B. F. Azar, and S. Talatahari, "Ant colony optimization for design of space trusses," International Journal of Space Structures, vol. 23, no. 3, pp. 167-181, 2008.

[3] S. Talatahari, M. Kheirollahi, C. Farahmandpour, and A. H. Gandomi, "Optimum design of truss structures using multi stage particle swarm optimization," Neural Computing \& Applications, 2012.

[4] S. Chen, Y. Zheng, C. Cattani, and W. Wang, "Modeling of biological intelligence for SCM system optimization," Computational and Mathematical Methods in Medicine, vol. 2012, Article ID 769702, 10 pages, 2012.

[5] S. Chen, Y. Wang, and C. Cattani, "Key issues in modeling of complex 3D structures from video sequences," Mathematical Problems in Engineering, vol. 2012, Article ID 856523, 17 pages, 2012.

[6] S. Chen, W. Huang, C. Cattani, and G. Altieri, "Traffic dynamics on complex networks: a survey," Mathematical Problems in Engineering, vol. 2012, Article ID 732698, 23 pages, 2012.

[7] F. Kang, J. Li, and Z. Ma, "Rosenbrock artificial bee colony algorithm for accurate global optimization of numerical functions," Information Sciences, vol. 181, no. 16, pp. 3508-3531, 2011.

[8] F. Kang, J. Li, and Z. Ma, "An artificial bee colony algorithm for locating the critical slip surface in slope stability analysis," Engineering Optimization, vol. 45, no. 2, pp. 207-223, 2013.

[9] P. Angeline, "Evolutionary optimization versus particle swarm optimization: philosophy and performance difference," in Proceedings of the Evolutionary Programming Conference, San Diego, Calif, USA, 1998.

[10] Y. Shi and R. C. Eberhart, "Fuzzy adaptive particle swarm optimization," in Proceedings of the Congress on Evolutionary Computation, pp. 101-106, May 2001.

[11] Y. Liu, Z. Qin, Z. Shi, and J. Lu, "Center particle swarm optimization,” Neurocomputing, vol. 70, no. 4-6, pp. 672-679, 2007.

[12] M. Xi, J. Sun, and W. Xu, "An improved quantum-behaved particle swarm optimization algorithm with weighted mean best position," Applied Mathematics and Computation, vol. 205, no. 2, pp. 751-759, 2008.

[13] B. Jiao, Z. Lian, and X. S. Gu, "A dynamic inertia weight particle swarm optimization algorithm," Chaos, Solitons and Fractals, vol. 37, no. 3, pp. 698-705, 2008.

[14] X. Yang, J. Yuan, J. Yuan, and H. Mao, "A modified particle swarm optimizer with dynamic adaptation," Applied Mathematics and Computation, vol. 189, no. 2, pp. 1205-1213, 2007.

[15] A. Kaveh and S. Talatahari, "A particle swarm ant colony optimization for truss structures with discrete variables," Journal of Constructional Steel Research, vol. 65, no. 8-9, pp. 1558-1568, 2009.
[16] A. Kaveh and S. Talatahari, "Particle swarm optimizer, ant colony strategy and harmony search scheme hybridized for optimization of truss structures," Computers and Structures, vol. 87, no. 5-6, pp. 267-283, 2009.

[17] P. C. Fourie and A. A. Groenwold, "The particle swarm optimization algorithm in size and shape optimization," Structural and Multidisciplinary Optimization, vol. 23, no. 4, pp. 259-267, 2002.

[18] A. Kaveh and S. Talatahari, "Hybrid algorithm of harmony search, particle swarm and ant colony for structural design optimization," in Studies in Computational Intelligence, vol. 239, pp. 159-198, Springer, Berlin, Heidelberg, 2009.

[19] A. Hadidi, A. Kaveh, B. Farahnadazar, S. Talatahari, and C. Farahmandpour, "An efficient hybrid algorithm based on particle swarm and simulated annealing for optimal design of space trusses," International Journal of Optimization in Civil Engineering, vol. 1, no. 3, pp. 377-395, 2011.

[20] J. F. Schutte and A. A. Groenwold, "Sizing design of truss structures using particle swarms," Structural and Multidisciplinary Optimization, vol. 25, no. 4, pp. 261-269, 2003.

[21] F. Kang, J. Li, and Q. Xu, "Damage detection based on improved particle swarm optimization using vibration data," Applied Soft Computing, vol. 12, no. 8, pp. 2329-2335, 2012.

[22] X. S. Yang, Nature-Inspired Metaheuristic Algorithms, Luniver Press, 2nd edition, 2010.

[23] A. Kaveh and S. Talatahari, "Charged system search for optimal design of frame structures," Applied Soft Computing, vol. 12, no. 1, pp. 382-393, 2012.

[24] American Institute of Steel Construction (AISC), Manual of Steel Construction Load Resistance Factor Design, AISC, Chicago, Ill, USA, 3rd edition, 2001.

[25] C. A. C. Coello, "Theoretical and numerical constraint-handling techniques used with evolutionary algorithms: a survey of the state of the art," Computer Methods in Applied Mechanics and Engineering, vol. 191, no. 11-12, pp. 1245-1287, 2002.

[26] A. Kaveh and S. Talatahari, "An improved ant colony optimization for the design of planar steel frames," Engineering Structures, vol. 32, no. 3, pp. 864-873, 2010.

[27] J. Kennedy and R. C. Eberhart, "Particle swarm optimization," in Proceedings of the IEEE International Conference on Neural Networks, vol. 4, pp. 1942-1948, December 1995.

[28] R. C. Eberhart and J. Kennedy, "A new optimizer using particle swarm theory," in Proceedings of the 6th International Symposium on Micro Machine and Human Science, pp. 39-43, Nagoya, Japan, October 1995.

[29] R. C. Eberhart and Y. Shi, "Comparing inertia weights and constriction factors in particle swarm optimization," in Proceedings of the Congress on Evolutionary Computation (CEC '00), pp. 8488 , July 2000.

[30] A. H. Gandomi, G. J. Yun, X. S. Yang, and S. Talatahari, "Combination of chaos and accelerated particle swarm optimization," Communications in Nonlinear Science and Numerical Simulations, vol. 18, pp. 327-340, 2013.

[31] C. V. Camp, S. Pezeshk, and G. Cao, "Optimized design of twodimensional structures using a genetic algorithm," Journal of Structural Engineering, vol. 124, no. 5, pp. 551-559, 1998.

[32] A. Kaveh and S. Shojaee, "Optimal design of skeletal structures using ant colony optimization," International Journal for Numerical Methods in Engineering, vol. 70, no. 5, pp. 563-581, 2007.

[33] A. Kaveh and S. Talatahari, "A discrete Big Bang-Big Crunch algorithm for optimal design of skeletal structures," Asian Journal of Civil Engineering, vol. 11, no. 1, pp. 103-122, 2010. 
[34] A. Kaveh and S. Talatahari, "Optimum design of skeletal structures using imperialist competitive algorithm," Computers and Structures, vol. 88, no. 21-22, pp. 1220-1229, 2010. 


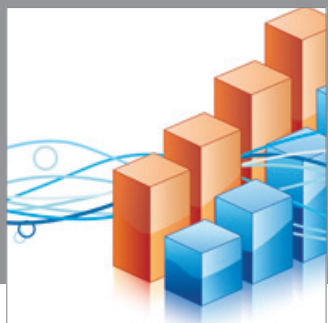

Advances in

Operations Research

mansans

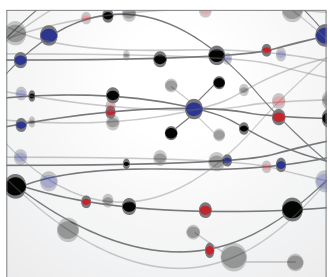

The Scientific World Journal
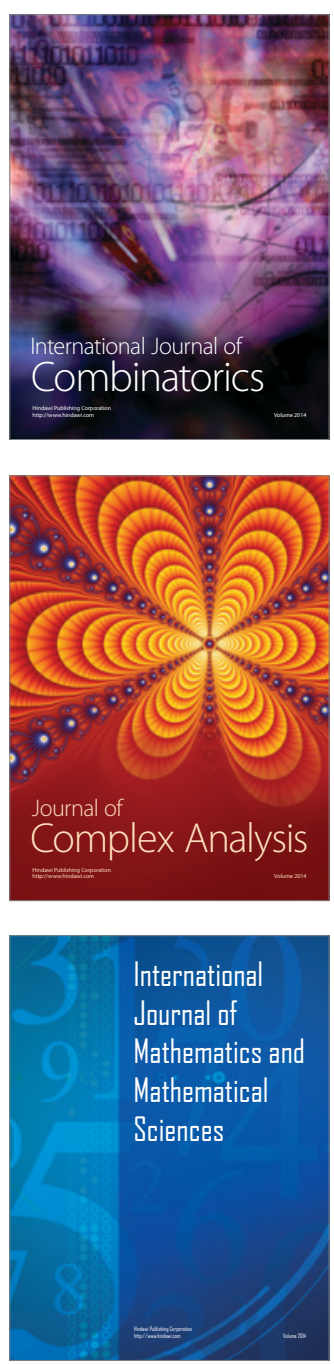
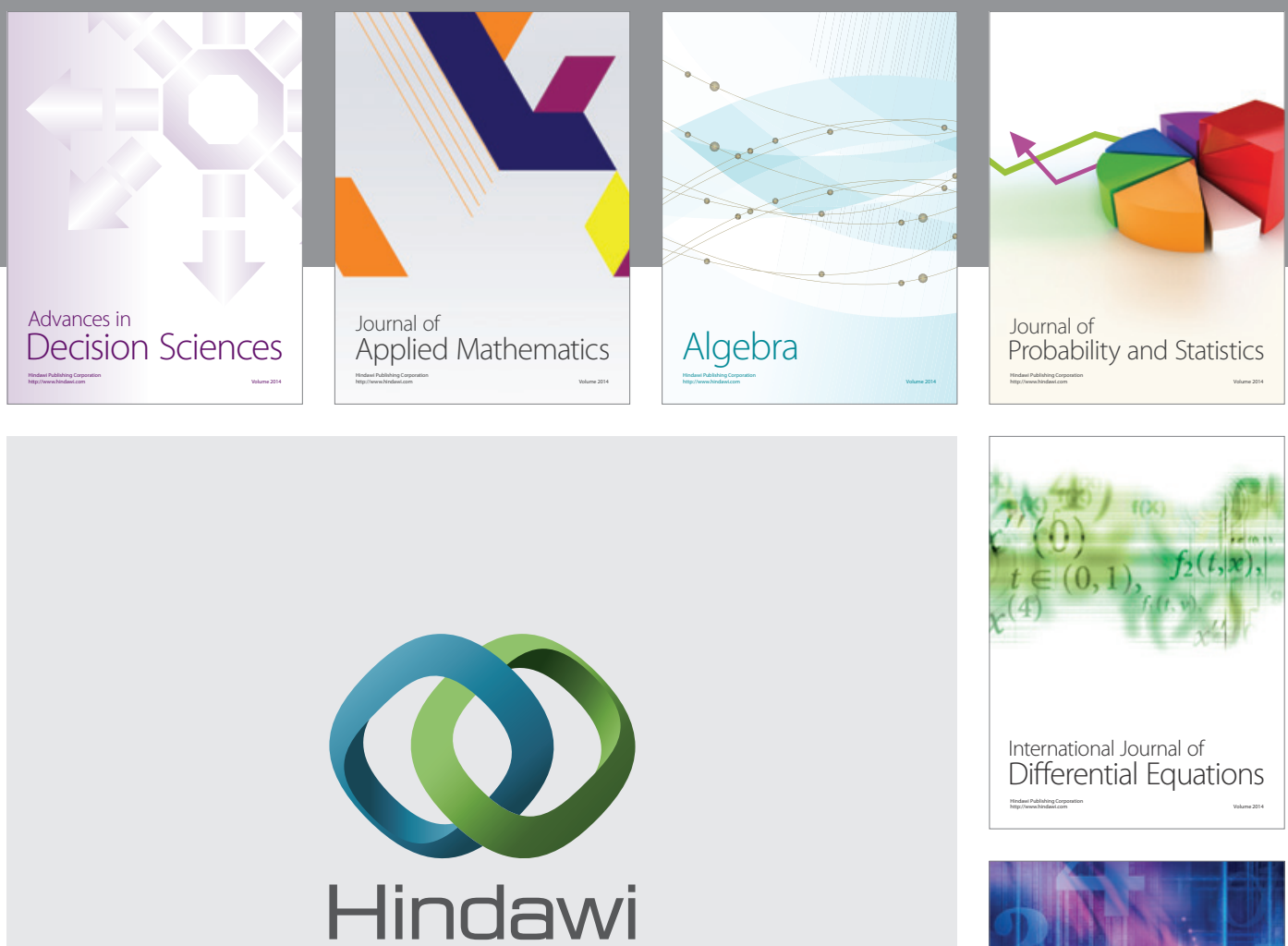

Submit your manuscripts at http://www.hindawi.com
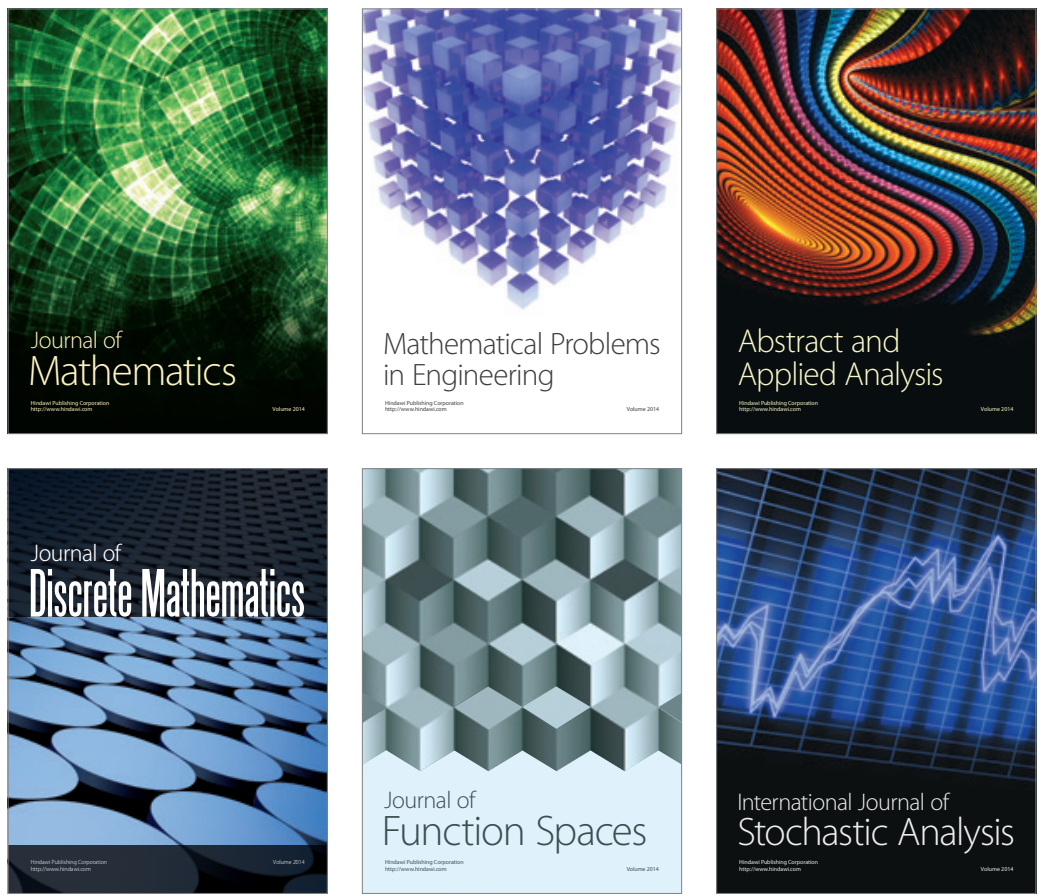

Journal of

Function Spaces

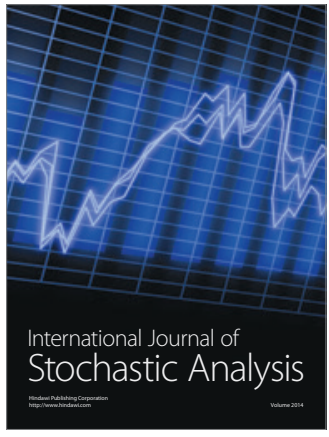

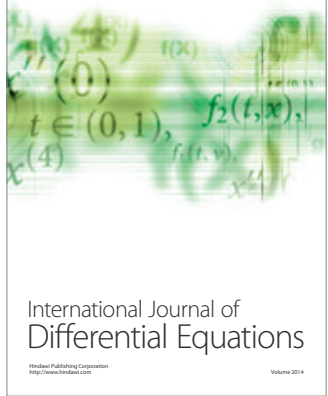
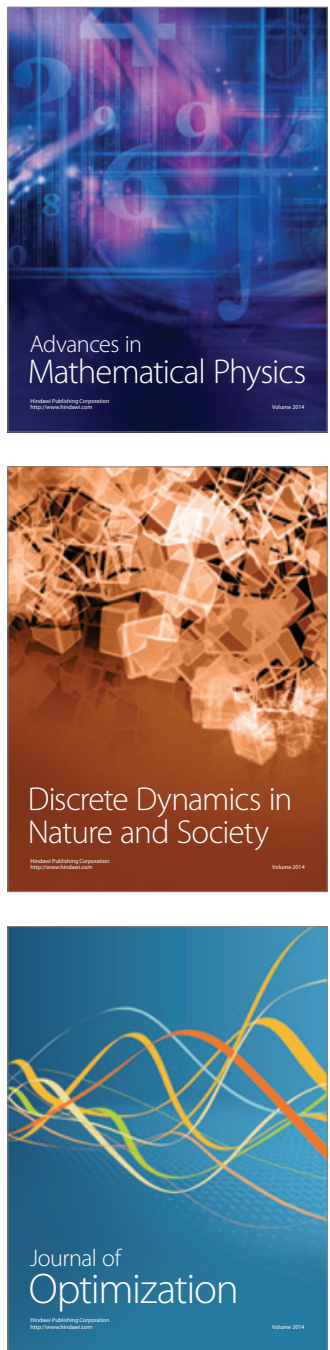